\title{
An Analysis on the Recessive Drain of College Teachers in Perspective of Psychological Contract
}

\author{
Shumao Zhang \\ School of Business Administration \\ Shenyang University \\ Shenyang 110044, China \\ E-mail: zsm0410@163.com \\ Xueli Huang \\ General Office of the People's Government of Liaoning Province \\ Shenyang 110032, China \\ E-mail: huangyu518@hotmail.com
}

\begin{abstract}
To study the recessive drain of college teachers is meaningful in practice. This paper, in perspective of psychological contract, analyzes the characteristics of psychological contracts of college teachers, the relationship between psychological contract breaches and recessive drain of college teachers, and the influencing factors of contract breaches, advancing relevant countermeasures for dealing with the recessive drain of college teachers from an angle of contract breaching process.
\end{abstract}

Keywords: College teacher, Recessive drain, Psychological contract

Along with the development of higher education in China, and the improvement of college teachers' economic treatments and social status, the drain of teachers has been relieved more or less. However, a recessive drain of teachers in colleges and universities tends to be more serious. The recessive drain means: Although teachers stay in their education positions, they devote themselves to businesses that have nothing to do with teaching and scientific research, which will finally cause a misplacement of the primary and the secondary. Studies show that psychological contracts impose certain inner drive on human behavior, which indicates employees' performances and attitudes at certain degree. In other words, it directly associates with the recessive drain of teachers. In order to make college teachers devote themselves to the education cause completely, to build up a positive psychological contract between college teachers and colleges is an effective way.

\section{The psychological contract's basic meanings and characteristics}

\subsection{The psychological contract's basic meanings}

The psychological contract is a kind of subjective psychological promise between the employee and the organization, in which each party promises to pay for what it should get from the other party. The core is the unwritten duties for each other. The psychological contract concept has been introduced into the management field since $60 \mathrm{~s}$ in $20^{\text {th }}$ century. An organizational psychologist Argyris firstly adopts the "psychological work contract" to explain the relationship between an employee and an employer in his book Understanding Organizational Behavior. Levinson, the "father of psychological contract", in his book Men, Management, and Mental Health advances that the psychological contract is "the sum of the implicit and unwritten mutual expectations between an organization and an employee". Based on preceding opinions that focus on expectations, Rousseau $(1990,1995)$ creatively puts forward that the psychological contract means responsibilities and obligations on the basis of promises. He gives a narrow definition of psychological contract at the individual level, namely: The psychological contract is a perception and belief system for mutual responsibilities and obligations between employees, in the interactive relationship between the organization and employees. The state of psychological contract has something to do with whether the organization commissions and 
obligations have been satisfied and executed fairly and honestly or not.

\subsection{The characteristics of college teachers' psychological contract}

Chinese college teachers' psychological contract, similar to common psychological contract, is characterized with subjectivity, fairness, frangibility, and dynamics. Besides, due to special cultural background and professional features, it has these characteristics as follow.

(1) The characteristics related with China's cultural background

The structure of psychological contract: China is characterized with group culture. It emphasizes on the collectivism, the harmonious interpersonal relationship, and interdependence. Chinese college teachers focus more on the harmony of interpersonal relationship. The psychological contract is liable to impacts of interpersonal relationship. Teachers have a strong consciousness of team cooperation, but the boundary of job responsibility is unclear. Most teachers prefer to sacrifice their personal time for work.

The contents of psychological contract: Chinese traditional culture lays stresses on the golden mean, pursuing for the great harmony and stability. In practice, most of teachers are satisfied with present conditions. The thought of "being a unit of the college" deeply roots in brains. Many teachers do not feel pressures or lacks of competitive consciousness. Professional titles, promotions, and trainings are all based on ages, what depresses young teachers' enthusiasm and creativity in work to certain degree. The distance between the upper level and the lower causes the problems in communication between college managers and teachers. Meanwhile, the psychological contract is a complex psychological activity. Its subjectivity and recessive character may lead to information asymmetry between teachers and the college (Weilin Cao, Yufang Dong \& Renfa Zhu, 2007, p. 94-96).

(2) The characteristics related with college teachers themselves

As knowledge workers, college teachers have high degrees, knowledge, and self-respects. Besides, their work time is more flexible. They hold stronger creativity and professional freedom in teaching and scientific research. In colleges, on one hand teachers pay attentions to material benefits. On the other hand, they are arrested by certain special affections on colleges and attracted by the vision of personal occupation development. Therefore, college teachers' psychological contract is self- determined and multi-dimensional.

\section{The breach of college teachers' psychological contract and the influencing factors}

\subsection{The breach of psychological contract}

The recessive drain of college teachers is mostly caused by the breach and violation of psychological contract. The breach of psychological contract means individuals' certain emotional experiences based on the recognition that the organization fails to fulfill the psychological contract. Its core emotion is the anger. Individuals feel certain unfair treatments and find that the organization breaks its commitment (Morrison \& Robinson, 1997). The breach of psychological contract takes employees' perception as the base and is impacted by individual experiences and values. It is characterized with the prominent individual subjectivity. Morrison \& Robinson advance the development model of psychological contract breach. According to this model, two factors contribute to the breach of psychological contract: the organization refuses to fulfill the commitment in purpose; the organization and employees' different recognitions to the commitment.

The dynamic model is displayed in Figure 1.

Turnley \& Feldman sort employees' behaviors that happen after the breach of psychological contract into four types: the first is to quit the job; the second is to decrease the professional performance; the third is to decrease the non-professional performance (mainly organizational citizen behavior, such as refusing to assume more duties, work overtime, or help colleagues); the fourth is certain anti-social behavior (such as revenging, damaging, stealing, and assaulting).

As college teachers perceive the breach or violation of psychological contract, few in better conditions may choose to quit the position, and seldom anti-social behaviors appear. Most teachers will decrease their professional or non-professional performances. Some may undertake the secondary occupation for the sake of economic benefits, instead of imputing energies in teaching. Some may refuse to follow the trend of college teaching, or explore new teaching methods, or lack of the consciousness of updating knowledge. They just wasting their time and teaching resources in a sense. Some may rush to the official stage for fames or interests. And some may compose papers or reports for professional promotion. All these facts contribute to the recessive drain of college teachers.

\subsection{The influencing factors for the recessive drain of college teachers due to psychological contract breach}

According to the model of psychological contract breach, the recessive drain of college teachers caused by the breach of psychological contract has something to do with the organization and individuals.

(1) The college institutional and management factor: Human behavior follows certain institutional norms and responses 
to the institution reasonably. Teachers' personal development and professional progress rely on certain institutional and management path. A positive institution, the effective management, and the school culture that cherishes credits can satisfy teachers' psychological expectation to a great degree, which can improve the fulfillment of commitment and reduce the breach of psychological contract. Contrarily, traditional administrative management idea and mode, ineffective communication, and unfair competition, promotion, and allocation mechanism merely emphasize on teachers' returns and short-term benefits. A personnel mechanism that neglects the differences of teachers' personal needs and psychological satisfactions will increase purposeful breaches of psychological contract and misunderstandings of psychological contract, which improves teachers' perception of the contract violation, leading to the psychological contract breaches, and generating the recessive drain of teachers.

(2) College teachers' personal factor: College teachers' individual behavior and response to certain circumstance is special. Studies show that it is easier for college teachers who have following characteristics to hold a subjective sense of psychological contract breach.

High neurotic teachers: In the organizational psychological contract relationship, high neurotic teachers may pay more attentions to the negative information of colleges. As the college faces reforms or certain negative information, this kind of teachers may criticize themselves in mind. Although real breaches do not happen in the college, the neurotic teachers may subjectively think breaches have already happened, which will lead to a sense of psychological contract breach in their minds.

Backbone teachers: As teachers think that they are irreplaceable because they play important roles or contribute a lot to the college, for example: extraordinary teaching performance and scientific research, important social relationship, and mastering special scientific research resources, they may expect too much of the college psychologically, and even hope that the college can satisfy them as their wills. Therefore, their senses of psychological contract breach are more popular and stronger.

Incompatible teachers: Incompatible teachers have poor interpersonal relationship and lower trust in others. They are liable to subjective senses of psychological contract breach. Due to poor interpersonal relationship, these teachers may pay more attentions to exterior negative factors. Low trust may make these teachers doubt the college's commitment and fulfillment, what will lead to the subjective sense of psychological contract breach.

\section{Countermeasures for maintaining psychological contract and reducing the recessive drain of college teachers}

\subsection{Build up a creditability and sincerity college culture and reduce purposeful breaches of contract}

In perspective of economics, if people can gains more benefits from opportunistic activities than costs, rational psychological contract subject may give up the credit and breach the contract in purpose. Therefore, in order to make psychological contract exert its special effects and drive two parties to fulfill relevant responsibilities, the college should build up and improve the creditability and sincerity college culture, and depress opportunistic activities in games. In the college aspect, firstly the college should set up and execute the "teachers-oriented" idea, give up outdated ideas that do not respect or trust teachers in traditional administrative management, form a college-and-teachers "life community", and found a base for realizing psychological contract management. Secondly, enhance the application and execution of the creditability and sincerity idea, build up an institutional default-constraint mechanism, reduce the impacts on the creditability and sincerity caused by leader replacement, policy alteration, and external environment changes, increase the default costs, decrease the purposeful breaches of psychological contract, especially the subjective senses of psychological contract breach, and reduce the recessive drain of college teachers.

\subsection{Improve bilateral communication between teachers and the college and reduce misunderstandings to psychological contract}

After a teacher has been employed by the college, it is a long process from making a commitment to fulfilling it. Therefore, this process is full of changes, what will easily cause misunderstandings and inconsistence. Communication can help to reduce inconsistence and misunderstandings of the contents of psychological contract. Besides, it can adjust the contents psychological contract in time. For college teachers, their work time is flexible and their work place is not fixed on one location. Chances for communication are few. Therefore, the college can inform teachers about college dynamics online, or regulates that all presidents of schools must communicate with teachers periodically. By this way, it can effectively reduce the inconsistence and misunderstandings, decreasing teachers' subjective senses of psychological contract breach.

\subsection{Improve the human resource management and reduce perceptions of psychological contract breach}

(1) Control the recruiting stage: Most of items in psychological contract are formed at the recruiting stage. In the recruiting process, the college should convey real information to teachers, avoiding the phenomenon that the college makes impractical commitments in order to attract more talents. Besides, the college should make implicit contents of psychological contract explicit. The college can inform teachers by all kinds of communication channels that it can 
satisfy or dissatisfy teachers' certain expectations under which kind of circumstance. Then, teachers' psychological expectations for the college will be more practical, what will relieve the sense of frustration and dissatisfaction caused by the college's default of commitment. Meanwhile, it makes teachers understand better that they should do what for the college in order to meet its expectations for them, creating an equal condition for the college fulfilling its commitment.

(2) Set up a fair management system: There is a comparison process from perceiving the contract default to the contract violation. A sense of fairness is an important factor that impacts this process. In order to solve the problem of teachers' recessive drain, the college should build up a fair and scientific management mechanism. The first is to ensure the fairness of decision-making mechanism. The construction of institutions should take teachers' opinions into consideration, which can objectively reduce the liberalism in constructing institutions and subjectively deepen teachers' understandings to institutions, reducing the sense of unfairness caused by indignities. Secondly, establish the fair and reasonable job evaluation mechanism. Job evaluation serves as important reference for promotions and salaries, and teachers' professional visions. At present, scientific research fruits are decisive factors in evaluating teachers' performances. In contrast, teaching is not so important. Besides, administrative power in the college is far higher than academic strength. Therefore, the college should, considering its development orientation, balance the relationship between teaching and scientific research, reduce administrative intervention, explore and design a reasonable job evaluation system. Only by this way, can it effectively reduce the breach of psychological contract, inspire teachers' enthusiasm and activity, and depress the recessive drain of teachers.

(3) Build up a multi-dimensional and self-serving incentive mechanism: As knowledge workers, college teachers are "complex people" who have various needs for economic benefits, interpersonal relationship, work environment, and professional development. Different types of teachers or similar teachers have different needs at different stages. Therefore, the college should, considering the practical conditions, build up a multi-dimensional incentive system, such as increasing salaries, improving welfare, offering more chances for trainings or professional promotions, and more freedom in work. Meanwhile, the college can adopt a self-serving incentive mechanism, constructing an "incentive supermarket". A teacher can select certain incentive method or the combination of several incentive methods that can satisfy his or her present dominated needs as much as possible after a period of hard work, which can decrease perceptions of psychological contract breach, improve work satisfaction, and reduce the recessive drain.

\section{Help teachers to realize right attribution and decrease psychological contract breaches}

Due to colleges' objective conditions and teachers' individual differences, to eliminate all perceptions of colleges violating or breaching their commitments is impossible. But to perceive the violation of contract does not necessarily drive a teacher to breach the contract. There is an explanation and attribution process. Attribution is a process in which people deduce the reasons for certain behavior, which determines teachers' responses to psychological contract breaches to a great degree. For teachers who attribute the unhappy things in work to themselves, such as individual abilities or endeavors, their contract breaching activities are maybe anything but not mindless teaching or playing at students. For teachers who attribute the unhappy things in work to colleges, their enthusiasm for work and loyalty to colleges will be degraded, which will lead to the recessive drain of college teachers. Therefore, the college should help teachers to realize right attribution by public reports and personal communication, reducing the appearance of psychological contract breaching activities.

\section{References}

Cao, Weilin, Dong, Yufang \& Zhu, Renfa. (2007). Research on the psychological contracts' fulfillment, violation, and breach, and the management. Modern Management Science, No.10, p. 94-96.

$\mathrm{Hu}$, Jiewang. (2005). The gravity of recessive losses of university teachers and a variety of losing ways. Higher Education in Chemical Engineering, No. 2, p. 81-85.

Sheng, Guangbin \& Xiao, Chuanliang. (2007). The universities teachers manage the psychological contract function and its construct. Journal of Jingmen Technical College, No.7, p. 56-58.

Tu, Haiyan \& Gong, Li. (2007). The characteristics of employees' psychological contract breaches and the countermeasures in management. Human Resource Development, No.10, p. 55-56.

Wang, Haiwei. (2007). The trans-cultural studies on university teachers' psychological contract. Forward Position, No.12, p.106-110. 


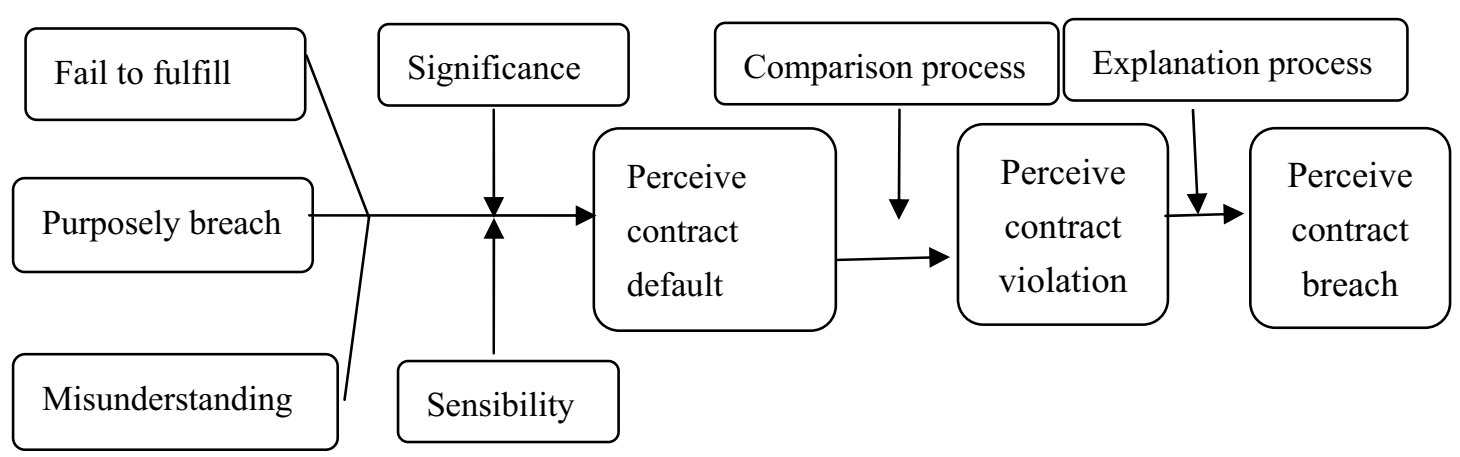

Figure 1. The Dynamic Model of Psychological Contract Breach 